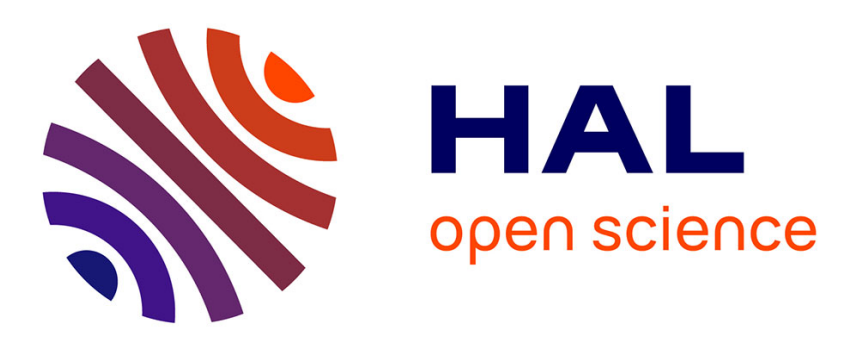

\title{
The phenotype of adult versus pediatric patients with inborn errors of metabolism
}

\author{
Jean-Marie Saudubray, Fanny Mochel
}

\section{To cite this version:}

Jean-Marie Saudubray, Fanny Mochel. The phenotype of adult versus pediatric patients with inborn errors of metabolism. Journal of Inherited Metabolic Disease, 2018, 41 (5), pp.753-756. 10.1007/s10545-018-0209-9 . hal-01957855

\section{HAL Id: hal-01957855 \\ https://hal.sorbonne-universite.fr/hal-01957855}

Submitted on 17 Dec 2018

HAL is a multi-disciplinary open access archive for the deposit and dissemination of scientific research documents, whether they are published or not. The documents may come from teaching and research institutions in France or abroad, or from public or private research centers.
L'archive ouverte pluridisciplinaire HAL, est destinée au dépôt et à la diffusion de documents scientifiques de niveau recherche, publiés ou non, émanant des établissements d'enseignement et de recherche français ou étrangers, des laboratoires publics ou privés. 


\title{
The phenotype of adult versus pediatric patients with inborn errors of metabolism
}

\author{
Jean-Marie Saudubray ${ }^{1} \cdot$ Fanny $_{\text {Mochel }}^{1,2,3,4}$ (D)
}

\begin{abstract}
Until recently, inborn errors of metabolism (IEM) were considered a pediatric specialty, as emphasized by the term "inborn," and the concept of adult onset IEM has only very recently reached the adult medical community. Still, an increasing number of adult onset IEM have now been recognized, as new metabolomics and molecular diagnostic techniques have become available. Here, we discuss possible mechanisms underlying phenotypic variability in adult versus children with IEM. Specifically, phenotypic severity and age of onset are expected to be modulated by differences in residual protein activity possibly driven by various genetic factors. Phenotypic variability may also occur in the context of similar protein expression, which suggests the intervention of environmental, ontogenic, and aging factors.
\end{abstract}

Keywords Inborn errors of metabolism · Phenotypic variability · Aging · Genetic factors · Ontogenic factors $\cdot$ Environmental factors

Until recently, inborn errors of metabolism (IEM) were considered a pediatric specialty. Indeed, in the mind of clinicians, the term "inborn" has for a long time meant a disease with onset in the newborn period or, at the latest, during childhood. Although pediatricians have learned that some IEM may have a slowly progressive course and that most IEM can present

Jean-Marie Saudubray and Fanny Mochel were involved in conception and design as well as drafting and revising the article.

Jean-Marie Saudubray jmsaudubray@orange.fr

$\triangle$ Fanny Mochel fanny.mochel@upmc.fr

1 Groupe de Recherche Clinique Neurométabolique, Université Pierre et Marie Curie, Paris, France

2 Centre de Référence Neurométabolique Adulte, Groupe Hospitalier Pitié-Salpêtrière, Paris, France

3 Sorbonne Universités, UPMC-Paris 6, UMR S 1127 and Inserm U 1127, and CNRS UMR 7225, and ICM, 75013 Paris, France

4 Assistance Publique-Hôpitaux de Paris, Département de Génétique, Groupe Hospitalier Pitié-Salpêtrière, Paris, France with mild forms, with the first clinical signs emerging in adolescence or even in adulthood, the concept of adult onset IEM has only very recently reached the adult medical community and remains one of the most intriguing questions in medicine. An increasing number of adult onset IEM have now been recognized, as new metabolomics and molecular diagnostic techniques have become available. Physicians caring for adults with IEM not only manage patients with late onset diseases but are also responsible for patients with early onset forms. A further important issue is the diagnosis of adult patient, who had their first clinical manifestations in childhood but in whom the diagnosis was missed. We will discuss below possible mechanisms underlying phenotypic variability in adult versus children with IEM.

The first group of mechanisms that comes to mind that may underlie phenotypic variability in IEM is a difference in the expression of the abnormal protein, often determined by genetic factors. Likewise, phenotypic severity and age of onset are expected to be modulated by differences in residual protein activity driven by (i) random $\mathrm{X}$ inactivation such as in ornithine transcarbamylase (OTC) deficiency, pyruvate dehydrogenase (PDH) deficiency, adrenomyeloneuropathy (AMN) or Fabry disease; (ii) genetic imprinting like in Niemann-Pick type A/B disease (Simonaro et al. 2006) or citrullinemia (Verma et al. 2017); (iii) somatic mosaicism like in OTC deficiency (Giorgi et al. 2000), PDH deficiency (Ridout et al. 
2008), AMN (Mochel, personal observation) or GLUT1 deficiency (Takahashi et al. 2017); (iv) composite heterozygosity between a pathogenic mutation and a modifier variant either in the same gene, as in maple syrup urine disease (MSUD) (Frézal et al. 1985), or in a different gene, as in fatty acid oxidation defect (Vockley et al. 2000) or OTC deficiency (Mira and Boles 2012) - the so-called synergistic heterozygosity; (v) mutational load (i.e., heteroplasmy) in mitochondrial DNA diseases like NARP/Leigh or MELAS syndromes; and (vi) functional consequences of the mutation that may lead to a conformational versus a metabolic defect like in triose phosphate isomerase deficiency (Orosz et al. 2009). Although not yet demonstrated in IEM, genetic resilience may also take place whereby a second genomic alteration compensate for the primary genetic defect (van Leeuwen et al. 2016).

Let us now consider phenotypic variability in the context of similar protein expression, which suggests the intervention of environmental, ontogenic and aging factors.

- Environmental factors play an important role in the precipitation of IEM at any age, but triggers of IEM mainly seen in adults encompass prolonged fasting, hypercatabolic status, certain diets or drugs. Likewise, pregnancies, which can favor both prolonged fasting due to hyperemesis gravidarum and/or increased energy demands during the puerperium, can reveal IEM in adults, especially urea cycle defects (Fassier et al. 2011; Weiss et al. 2018). The long-term accumulation of toxic metabolites can also be at stake in some typical adult onset IEM such as Refsum disease with a demyelinating neuropathy associated with high levels of phytanic acid and hereditary sensory neuropathies type I related to SPTLC1/SPTLC2 mutations, which lead to the accumulation of deoxysphingolipids and share common pathogenic mechanisms with diabetic neuropathies (Mwinyi et al. 2017).

- Ontogenic factors may underlie important phenotypic variability in IEM as metabolic networks and interorgan interactions evolve with age. This is especially true for IEM manifesting with two waves, an initial phase in childhood predominantly affecting the liver and reflecting the prominent role of these hepatic pathways early in life, and a subsequent phase in adolescence or adulthood affecting the central nervous system and reflecting long-term consequences of altered homeostasis of cholesterol and/or bile acids. Likewise, patients may present with transient neonatal hepatic manifestations (cholestasis, liver failure) followed many years later by a progressive neurodegenerative disease sometimes after a long free interval (Saudubray and Garcia Cazorla 2016) such as in cerebrotendinous xanthomatosis (cataract, spasticity, ataxia, peripheral neuropathy, psychosis)
(Degos et al. 2016), spastic paraplegia type 5 (CYP7B1 mutations) (Marelli et al. 2018), Niemann-Pick type C disease (cognitive decline, ataxia, movement disorders) (Patterson et al. 2013), and MEGDEL syndrome (dystonia with Leigh like encephalopathy) (Maas et al. 2017; Giron et al. 2018). Other IEM reflect changes in metabolic pathways with age such as ornithine amino transferase (OAT) deficiency. In the neonate, OAT is orientated towards ornithine and arginine production but then switch in the first year of life to ornithine catabolism leading to pyrroline-5-carboxylic acid. Hence, OAT deficiency may present as an urea cycle disorder early in infancy with low ornithine and citrulline plasma levels while it presents in adolescence as a progressive gyrate atrophy with marked hyperornithinemia (Cleary et al. 2005). Similarly, age-specific disease manifestations have been well-delineated for (i) metabolic crises in glutaric aciduria type 1 , in which there is almost no risk of crisis anymore after 36 months of age (Kolker et al. 2006); (ii) mutations in the TRMU gene, encoding a mitochondria-specific tRNA-modifying enzyme requiring sulfur and in which liver failure mostly occurs at 2-4 months of age, possibly related to limited availability of cysteine then, with no recurrence in patients who survive the neonatal episode (Zeharia et al. 2009); and (iii) medium chain acyl-CoA dehydrogenase (MCAD) deficiency, which may lead to neonatal death, hypoketotic hypoglycaemia, or no symptoms, as MCAD is not a limiting enzyme of the mitochondrial fatty acid oxidation pathway-very long chain fatty acid dehydrogenases and the trifunctional enzyme being able to ensure several $\beta$-oxidation cycles. Brain energy metabolism also varies largely with age. In the first weeks of life, the brain relies mainly on ketone bodies but progressively glucose becomes the main substrate. In adults, the uptake of glucose decreases with age while the uptake of acetoacetate remains relatively spared, raising the question whether ketones can compensate for deteriorating brain glucose uptake during aging and neurodegenerative conditions (Nugent et al. 2014). It is therefore of further interest that the phenotype of patients with GLUT1 deficiency may evolve strikingly with age, children usually presenting with a prominent epileptic syndrome whereas adults instead manifest non-epileptic paroxysmal disorders (Gras et al. 2014).

- As illustrated above, aging is accompanied by important changes in the relative importance of metabolic pathways and metabolic substrates, which, along with genetic factors, likely contribute to phenotypic variability between children and adults with IEM. Furthermore, aging itself may influence the expression of IEM due to additional cellular modifications. This is especially true for the maintenance of energy homeostasis in the nervous system that 
is challenged with cellular aging. Likewise, late onset forms of some IEM may reflect primarily altered neuronal or glial energy homeostasis with age, like long-chain acylCoA dehydrogenase deficiency or peroxisome biogenesis defects presenting with adult onset sensory neuropathy and/or retinal degeneration. Energy homeostasis is also key for myelin maintenance, which could explain the changing spectrum of several energetic disorders like late onset PDH or biotinidase deficiency that present with adult onset optic atrophy potentially reversible on high doses of vitamin B1 (Sedel et al. 2008) and biotin (Ramaekers et al. 1992) respectively. These examples illustrate the need for more standardized evaluation of the benefit of energy replenishment therapies in various neurodegenerative and neurometabolic diseases (Adanyeguh et al. 2015; Garcia-Cazorla and Saudubray 2018, in revision). Furthermore, mitochondrial DNA mutations accumulate with age and this phenomenon is thought to modulate the risk for neurodegenerative diseases like Parkinson disease (Dölle et al. 2016), but likely neurometabolic diseases as well. Aging is also associated with increasing somatic mutations (Lodato et al. 2018), defective autophagy and increased risk for protein aggregation which may, in the context of a metabolic susceptibility like decreased glucocerebrosidase activity, accelerate neurodegeneration (Mazzulli et al. 2011).

In summary, mechanisms underlying pediatric versus adult phenotypic differences are numerous and still not well understood. Indeed, the phenotype (characteristic features of an organism) is the net sum of hereditary and environmental factors. It depends on phenotypic plasticity (modulations in response to changes in the environment) and is agedependent (ontogenic changes and aging). Rather than analytical approaches focusing only on genotype-phenotype correlations, it is important to explore pathophysiological mechanisms based on an integrated approach that takes into account changes in metabolic pathways and substrates with age as well as the impact of environmental factors and aging. This underscores the need for maintaining and further developing a strong capacity for metabolic investigations in biochemical genetic labs (e.g., metabolomics, lipidomics) besides their increasing access to next generation sequencing. Indeed, metabolomics and lipidomics stand out among omics as the study of the end products of cellular processes, therefore are more likely to be representative of clinical phenotypes than genetic variants or changes in gene expression. A greater understanding of phenotypic variability will be critical to personalize, or at least weigh, the initiation of long-term, sometimes burdensome, therapies in diseases detected by expanded newborn screening but that can manifest only in adulthood and with milder phenotypes like AMN.

\section{Compliance with ethical standards}

Conflict of interest Jean-Marie Saudubray and Fanny Mochel declare that they have no conflict of interest.

\section{References}

Adanyeguh IM, Rinaldi D, Henry PG et al (2015) Triheptanoin improves brain energy metabolism in patients with Huntington disease. Neurology 84:490-495

Cleary MA, Dorland L, de Koning TJ et al (2005) Ornithine aminotransferase deficiency: diagnostic difficulties in neonatal presentation. J Inherit Metab Dis 28:673-679

Degos B, Nadjar Y, Amador M del M et al (2016) Natural history of cerebrotendinous xanthomatosis: a paediatric disease diagnosed in adulthood. Orphanet J Rare Dis 11:41-44

Dölle C, Flønes I, Nido GS et al (2016) Defective mitochondrial DNA homeostasis in the substantia nigra in Parkinson disease. Nat Commun 7:13548-13558

Fassier T, Guffon N, Acquaviva C, D'Amato T, Durand DV, Domenech P (2011) Misdiagnosed postpartum psychosis revealing a late-onset urea cycle disorder. Am J Psychiatry 168:576-580

Frézal J, Amédée-Manesme O, Mitchell G et al (1985) Maple syrup urine disease: two different forms within a single family. Hum Genet 71 : 89-91

Garcia-Cazorla A, Saudubray JM (2018) Cellular neurometabolism: a tentative to connect cell biology and metabolism in neurology. J Inherit Metab Dis, in revision

Giorgi M, Morrone A, Donati MA et al (2000) Lymphocyte mRNA analysis of the ornithine transcarbamylase gene in Italian OTCD male patients and manifesting carriers: identification of novel mutations. Hum Mutat 15:380-381

Giron C, Roze E, Degos B, et al (2018) Adult-onset generalized dystonia as the main manifestation of MEGDEL syndrome. Tremor Other Hyperkinet Mov (N Y) In press

Gras D, Roze E, Caillet S et al (2014) GLUT1 deficiency syndrome: an update. Rev Neurol (Paris) 170:91-99

Kolker S, Garbade SF, Greenberg CR et al (2006) Natural history, outcome, and treatment efficacy in children and adults with glutarylCoA dehydrogenase deficiency. Pediatr Res 59:840-847

Lodato MA, Rodin RE, Bohrson CL et al (2018) Aging and neurodegeneration are associated with increased mutations in single human neurons. Science 359:555-559

Maas RR, Iwanicka-Pronicka K, Kalkan Ucar S et al (2017) Progressive deafness-dystonia due to SERAC1 mutations: a study of 67 cases. Ann Neurol 82:1004-1015

Marelli C, Lamari F, Rainteau D et al (2018) Plasma oxysterols: biomarkers for diagnosis and treatment in spastic paraplegia type 5 . Brain 141:72-84

Mazzulli JR, Xu YH, Sun Y et al (2011) Gaucher disease glucocerebrosidase and $\alpha$-synuclein form a bidirectional pathogenic loop in synucleinopathies. Cell 146:37-52

Mwinyi J, Boström A, Fehrer I et al (2017) Plasma 1-deoxysphingolipids are early predictors of incident type 2 diabetes mellitus. PLoS One 12:e0175776

Mira V, Boles RG (2012) Liver failure with coagulopathy, hyperammonemia and cyclic vomiting in a toddler revealed to have combined heterozygosity for genes involved with ornithine transcarbamylase deficiency and Wilson disease. JIMD Rep 3:1-3

Nugent S, Tremblay S, Chen KW et al (2014) Brain glucose and acetoacetate metabolism: a comparison of young and older adults. Neurobiol Aging 35:1386-1395 
Orosz F, Olah J, Ovadi J (2009) Triosephosphate isomerase deficiency: new insights into an enigmatic disease. Biochim Biophys Acta 1792:1168-1174

Patterson MC, Mengel E, Wijburg FA et al (2013) Disease and patient characteristics in NP-C patients: findings from an international disease registry. Orphanet J Rare Dis 8:12-21

Ramaekers VT, Suormala TM, Brab MR, Duran M, Heimann G, Baumgartner ER (1992) A biotinidase Km variant causing late onset bilateral optic neuropathy. Arch Dis Child 67:115-119

Ridout CK, Brown RM, Walter JH, Brown GK (2008) Somatic mosaicism for a PDHA1 mutation in a female with pyruvate dehydrogenase deficiency. Hum Genet 124:187-193

Saudubray JM, Garcia Cazorla A (2016) Clinical approach to inborn errors of metabolism in pediatrics. In: Saudubray JM, Baumgartner $\mathrm{M}$, Walter $\mathrm{J}$ (eds) Inborn metabolic diseases 6th edition. Springer Heidelberg, vol 629, pp 2-70

Sedel F, Challe G, Mayer JM et al (2008) Thiamine responsive pyruvate dehydrogenase deficiency in an adult with peripheral neuropathy and optic neuropathy. J Neurol Neurosurg Psychiatry 79:846-847

Simonaro CM, Park JH, Eliyahu E, Shtraizent N, McGovern MM, Schuchman EH (2006) Imprinting at the SMPD1 locus: implications for acid sphingomyelinase-deficient Niemann-Pick disease. Am J Hum Genet 78:865-870

Takahashi S, Matsufuji M, Yonee C, Tsuru H, Sano N, Oguni H (2017) Somatic mosaicism for a SLC2A1 mutation: implications for genetic counseling for GLUT1 deficiency syndrome. Clin Genet 91:932-933

van Leeuwen J, Pons C, Mellor JC et al (2016) Exploring genetic suppression interactions on a global scale. Science 354:599

Verma M, Charles RCM, Chakrapani B et al (2017) PRMT7 interacts with ASS1 and citrullinemia mutations disrupt the interaction. J Mol Biol 429:2278-2289

Vockley J, Rinaldo P, Bennett MJ, Matern D, Vladutiu GD (2000) Synergistic heterozygosity: disease resulting from multiple partial defects in one or more metabolic pathways. Mol Genet Metab 71: $10-18$

Weiss N, Mochel F, Rudler M et al (2018) Peak hyperammonemia and atypical acute liver failure: the eruption of an urea cycle disorder during hyperemesis gravidarum. J Hepatol 68:185-192

Zeharia A, Shaag A, Pappo O et al (2009) Acute infantile liver failure due to mutations in the TRMU gene. Am J Hum Genet 85:401-407 